\title{
Job and housing tenure and the journey to work
}

\author{
David M. Levinson \\ 1822 Francisco St. \#11, Berkeley, CA 94703, USA (e-mail: dmlevins@uclink2.berkeley.edu)
}

Received: June 1995 / Accepted in revised form: May 1997

\begin{abstract}
Tenure at jobs and houses, along with commuting patterns between home and work, were studied for residents of metropolitan Washington. Two alternative potential outcomes were considered: (1) because moving or switching jobs can be used as an opportunity to reduce commuting duration in an era of rising congestion, those who recently moved or changed jobs should have shorter than average commutes; and (2) because most new residential construction is at the urban fringe, an area of longer commutes, those who recently moved to new homes should have longer commutes. Evaluation of the effect of commuting duration on job and housing tenure suggests that those who move, on average, maintain commute duration rather than having a major increase or decrease. This corroborates the idea that there are offsetting factors, where increases in commute lengths due to suburbanizing residences are counteracted by the correlated process of suburbanizing jobs.
\end{abstract}

\section{Introduction}

The influence of commuting time on long term employment and residential relationships should be an important issue for policy makers, planners, and regional scientists. The remarkable constancy of commuting durations over the past 40 years despite rising congestion and lengthening commutes (Levinson and Kumar 1994a,b) suggests the need for an explanatory theory. This paper attempts to develop such a theory, and test some of its consequential hypotheses with data from metropolitan Washington.

There are at least two prisms through which the process of containment of commuting costs can be viewed. The first approach, traditional in urban economics and travel demand theory, conceives of the city as being in static equilibrium, where individuals trade-off housing and transportation costs to maximize a narrowly defined "utility". In the second dynamic, or evolu- 
tionary, approach, decisions constitute a process rather than specific events, and costs are not limited to housing and transportation, but include relocation and transaction costs, crucial to explaining the disequilibrium seen in real cities.

In the equilibrium approach, spatial separation, as measured by travel time, along with the price of land, housing, and commercial development serve as the central variables. It is assumed that aggregate demand curves (e.g. willingness to commute daily a certain amount) and aggregate supply curves (e.g. number of jobs at a given time-distance away from home) intersect at the average price (commute time). However, it has been found that the amount of travel far exceeds the "minimum required commute" (Giuliano and Small 1993). This suggests that location and commuting decisions include factors beyond simple commuting times, wage rates, and housing prices.

In an evolutionary approach, travel time still matters, but additional questions are raised concerning length of stay of individuals in jobs and residences. Since not everyone simultaneously seeks new housing or jobs in the dynamic model (Vickerman 1984), there needs to be some understanding of how often these transactions are made, and what are the factors which influence them. Further, there should be an attempt at understanding how relocation and travel times interact. Behaviors, such as living in a home or holding a certain job, continue until something actively changes them. This perspective opens up interesting behavioral questions about what is necessary for an individual, household, or firm to consciously decide to change a habit. Other questions ask how often habits are re-evaluated, and what is the degree of re-evaluation (ranging, from, for instance, the notion of looking for something else after a bad day at work, to the more serious quitting of a job). While application of this line of thinking to the full gamut of questions falls beyond the scope of a single piece of research, we can begin looking at some of the questions of urban spatial dynamics.

Earlier research has approached the behavioral question, "Do commutes lengthen or shorten when firms relocate to the suburbs?" Bell (1991), studying a firm in Melbourne, Australia, found that average commuting duration for employees of the firm declined by $10 \mathrm{~min}$ each way after the firm subuarbanized from a downtown location. Daniels (1972), examining Britain, and Cervero and Landis (1992), investigating San Francisco, reported relatively constant commuting times before and after relocation. A similar analysis of a health care firm in Los Angeles shows that as the firm has added offices in suburban locations, average commuting distances have dropped between 1984 and 1990, while times have increased due to rising congestion (Wachs et al. 1993).

Fewer studies have looked at this question from the perspective of the individual. "After a household moves or an individual changes his job location, does the commute become longer or shorter?" Clearly commuting is a diseconomy, and congestion over the years increases the peak period travel time between places, so the opportunity to relocate could be used to save 
time. However, the areas of highest growth, and the most recent relocation, for housing are in the outer suburbs (though what constitutes "outer" changes over time), the areas with the lowest access to jobs, requiring a resident to travel further to reach the same number of opportunities than his colleague in the city. This paper uses a survey conducted in metropolitan Washington DC in the early 1990's to re-examine the interaction of tenure (defined here as the length of stay in a house or with a firm) and commuting distance and duration.

Tenure or duration of stay, and its reciprocal, the frequency of relocation or switching, has been well researched. A preliminary search of the library catalog at the University of California turned up well over a hundred studies with the keywords residential (or housing) mobility, job mobility, residential (or housing) tenure, or job tenure. Some reviews of this literature include Bennett and Gade (1979), Cadwallader (1992), Clark and Moore (1980), and Fredland (1974). But only a few also concerned transportation. Verster (1985), studying the Netherlands, found that both the marginal probability of moving after a job change and conditional destination choice are influenced significantly by travel cost variables. Kingkade (1983) studied similar issues in Rhode Island, finding that workplace changes preceded shifts in housing location, which were made to provide reasonable commuting duration for individuals.

Furthermore, most integrated land use and transportation models, which consider dynamics, use fixed empirical results concerning relocation (Wegener 1994). Hayashi and Tomita (1989) develop a micro-simulation approach to investigate changes on mobility decisions caused by transportation improvements, positing that the probability of a household moving depends on the utility of the current location, which was found, in part, to be a function of its accessibility.

This paper proceeds as follows: First is the development of theory relating job and housing tenure with changes in urban form and commuting. This is followed by discussions of the region of study and the data used in the empirical analysis. Next, the paper examines the data through cross-tabulations and regression analysis. The variables dealing with location, commuting time, co-tenure, demographics, income, employment conditions, and housing status, are examined in turn. The paper concludes with directions for additional study.

\section{Theory}

We begin with the observation that, over many years, intra-metropolitan commuting times between home and work have remained fairly stable despite increased trip-making, rising congestion, and major changes in the constituency of the labor force. This suggests that there is an underlying preference for expending a limited amount of time in travel. However the idea of such an underlying preference does not deny that there are clearly trade-offs on the time-dimension between travel and non-travel activities; 
on the money dimension between housing, travel, and other expenses; and between time and money, as more individuals work they earn more money, which, reaffirming the idea of economies through the division of labor, enables them to purchase services they used to perform themselves, such as personal services, eating out, and child care.

Just as on the individual side, there are also trade-offs on the employer side. Employers weigh accessibility to other employers, access to labor markets, and the cost of office space, among other factors, when locating. Location in the center of an idealized region maximizes accessibility, and theory suggests it would also result in the highest rents. However, since the firm is not employing everyone in the region, it may be able to locate away from the center and achieve economies on both rents and the wage rates needed to entice good workers. By saving its workers both housing costs and travel time, the firm becomes a more attractive match. One disadvantage is that expenses on interfirm exchange may rise, though this depends very much on the nature of the firm's business.

This process manifests itself as the region grows in population and area: individuals trying to maximize the benefits from housing and minimize on commuting will on average move farther and farther from the center of the region. While the first moment, the center of population may remain fixed, the second moment, the average distance from the center, increases over time. If employment remained in the center of the region, we would expect that this would result in an increase in journey to work times. However, the location of housing is not independent of the location of employment. The second component of this process is employer location, as the labor force is moving farther and farther out, it becomes more and more to the firm's advantage to suburbanize as well.

It is remarkable that with this entire dynamic in place, commuting times remain essentially unchanged. The suburbanization of jobs and housing, without any joint location decisions, would result in a large amount of cross-commuting and an increase in travel times. However, while distances have increased to take advantage of faster suburb-suburb links, travel times have not. This mechanism has been dubbed the "mutual co-location of jobs and houses", which is concomitant with a reconstruction of the urban form and the location of specific individual households and firms within the city to contain commuting costs.

The process of incorporating growth and change in the metropolitan region within the individual's goal of achieving the best possible situation at the least cost takes place over a period of years. Individuals do not choose instantaneously to relocate their households or take new jobs in order to arbitrage minute differences in their current housing/travel situation and their preferred one. The key disadvantage to immediate arbitrage are the transaction costs of locational and job change, including the cost of obtaining information as well as the cost of relocating, neither of which are insignificant.

The absence of immediate arbitrage suggests that job and housing tenure are key questions to explore when studying changes in urban form to 
measure the combined economic and social transaction costs of relocation. Tenure is defined here as the number of years to date that an individual has been with an institution (their job or their home). Those with the shortest tenure have most recently switched.

There are two offsetting factors which indicate a priori that it is unclear from theory whether housing relocation will lead to longer or shorter commutes. On the one hand, since moving or switching jobs can be used as an opportunity to reduce commuting duration in an era of rising congestion, those who recently moved or changed jobs should have shorter than average commutes. On the other hand, because most new residential construction is at the urban fringe, an area of longer commutes, those who recently moved to new homes should have longer commutes.

From an idealized perspective, we can visualize a city of radial and ring roads about a center. Both jobs and housing are located at various points throughout the city. Individuals when choosing where to locate their home or take a job, select both which radial and which ring (or distance from the center) to be on. New housing growth is taking place at the outermost rings, so we expect those rings to have the population with the shortest tenure. However this does not lead to a definite prediction of whether relocation lengthens or shortens commutes. For instance, assume an individual is moving homes while keeping a job. That individual can relocate at a ring farther out from his employer and still have a shorter commute than someone on the same ring, so long as the radial roads on which his home and work are located have a sufficiently small angle between them. But whether this is the case is an empirical matter, mathematical reasoning alone cannot tell us commuting costs, except in idealized cases such as the case of a single center where all jobs locate or where we assume perfect entropy, where jobs and houses are mutually co-located only with respect to being in the same city, but beyond that no attempt is made to conserve commuting costs. The issue is further complicated by multiple worker households. Adding to the complexity of the problem is the concurrency of decisions to take a new job and the decision to move homes.

By looking at the factors influencing tenure at the home and workplace in this paper, the empirical question is tested as to which, if either, consequence is larger: relocation leads to longer commutes or relocation leads to shorter commutes.

Two models are constructed with the dependent variable being workplace and housing tenure in years ( $\mathrm{Yw}, \mathrm{Yh})$, respectively. A number of independent factors are considered, subscripted to indicated whether they are associated with the household or individual (i), commute (hw), or the location of home (h) or workplace (w), which are discussed in more depth below. The variables include the interaction of housing tenure on job tenure ( $\mathrm{Yh}$ or $\mathrm{Yw}$ ), housing type (Ti), age of the individual (Ai), gender (Gi), household size (Si), income (Ii), employer type (ETi), schedule flexibility (SFi), schedule stability (SSi), employer attitude to work at home (EAi), the location of the house in the urban ring (Lh) which is a surrogate for the age or material duration of the housing stock as well as the accessibility to 
opportunities (jobs and competing workers) and the location of the job (Lw) which is similarly a crude surrogate for the age of the workplace and accessibility at the employment end, and home to work commuting times (Chw) and quality (Qhw). This is represented below:

Yw $=f(Y h, A i$, Gi, Si, Ii, ETi, SFi, SSi, EAi, Lh, Lw, Chw, Qhw)

$\mathrm{Yh}=\mathrm{f}$ (Yw, Ai, Gi, Si, Ii, Eti, SFi, SSi, EAi, Lh, Lw, Chw, Qhw).

\section{Region of study}

The author selected Montgomery County, MD as a case study because of familiarity with the region and because of the region's dynamic nature. Montgomery County, Maryland, the suburban jurisdiction immediately to the northwest of Washington, DC, had 750000 residents and 415000 jobs in 1990. In the past few decades, the county has grown rapidly in both population and employment and has emerged as a major employment center. Data for metropolitan Washington and Montgomery County, Maryland show large changes over the preceding twenty years, 1968-1988: a) population in the region increased by $30 \%$; b) at-place employment increased by $85 \%$; c) the average household size dropped from 3.34 to 2.67 ; d) vehicle registrations (including passenger cars, vans, and light trucks) rose by $118 \%$; e) autos per household increased from 1.6 to 2.0 , while autos per person increased from 0.48 to 0.73 during this period; f) road capacity as measured in lane miles of state roads in the county increased by only $13 \%$; g) annual vehicle miles of travel in the county increased by $133 \%$ (Levinson and Kumar 1994b). Qualitatively, Knox (1991) identifies large modifications in the Washington region's built environment resulting from changes in the orientation of various building professions (developers, architects, planners) as well as consumers. Recently introduced elements include masterplanned communities, high-tech corridors, mixed use zoning, festival marketplaces, gentrification, historic preservation, and postmodern architecture. The new housing market is mostly replacements, with two thirds for move-ups rather than new entrants (migrants from other regions or first time buyers (migrants over time)).

Knox (1991) reports that while for the metropolitan area, $15.9 \%$ of households earned greater than $\$ 75000$ per year, in Montgomery County 23.7\% did. The 1985 average household income of $\$ 42000$ in the metro area was $50 \%$ greater than the national average. The metropolitan area is highly educated, with one-third of adults having graduated college as opposed to only one-fifth nationally.

\section{Data}

The Montgomery County Travel Survey (conducted in 1991) is the first phase of what was intended to be a multi-year longitudinal survey garner- 
ing in-depth information about the travel behavior of a panel of Montgomery County residents (Kumar and Replogle 1992; MCPD 1993). Analysis of individuals before and after moves using future waves of this survey will enhance our understanding of this critical issue, but at present those data are unavailable. However, we can use the survey for a cross-sectional analysis. The survey asks two questions which can help us understand the influence of relocation on the journey to work. The first is: How long have you lived in your current residence? the second is: How long have you been with your current employer? These serve as dependent variables for the regression later in this paper. It should be noted that the second question does not concern work location directly, so an individual can be with the same employer, although the employer changed locations. (In this paper, the terms firm, employer, and agency are considered synonymous and used interchangeably, and are not intended to differentiate between public or private sector employment.)

\section{Regression: hypotheses and results}

There are a number of factors which are expected to influence tenure at a job or house. These include metropolitan location, commuting variables, income indicators, employment factors, and demographics, as well as tenure at the other. Table 1 shows a cross-tabulation of distance from the center of the region, accessibility, home price, housing tenure, and commuting time. Table 2 shows the interaction of housing and job tenure. Table 3 displays the mean commuting duration by job and housing tenure. Table 4 shows the mean value of variables and a regression of those variables on job and housing tenure. The tables will be discussed in more depth below. This section will discuss the hypotheses about each variable and then present the results of two ordinary least squares regressions to test the hypotheses. However, it should be noted that the literature on the influence of a number of these effects is ambiguous, with different analyses producing varying magnitudes and signs of the coefficients (Quigley and Weinberg 1977; Verster 1985; Cadwallader 1992).

\section{Location}

Previous research has found that the amount of residential stability increases with increasing distance from the Central Business District (Cadwallader 1982; Moore 1971), where stability is defined as the number of people residing in the same house in one year as had done so in a previous time period (five or ten years before). However, that finding negates the effects of growth and new construction. Table 1 shows a cross-tabulation of accessibility to jobs and housing by auto and transit, average length of residence, home price, and mean commuting duration and distance, with distance from the center of the region. It is observed that growth is fastest at the edge of the region, so the homes are newest, as demonstrated by a 


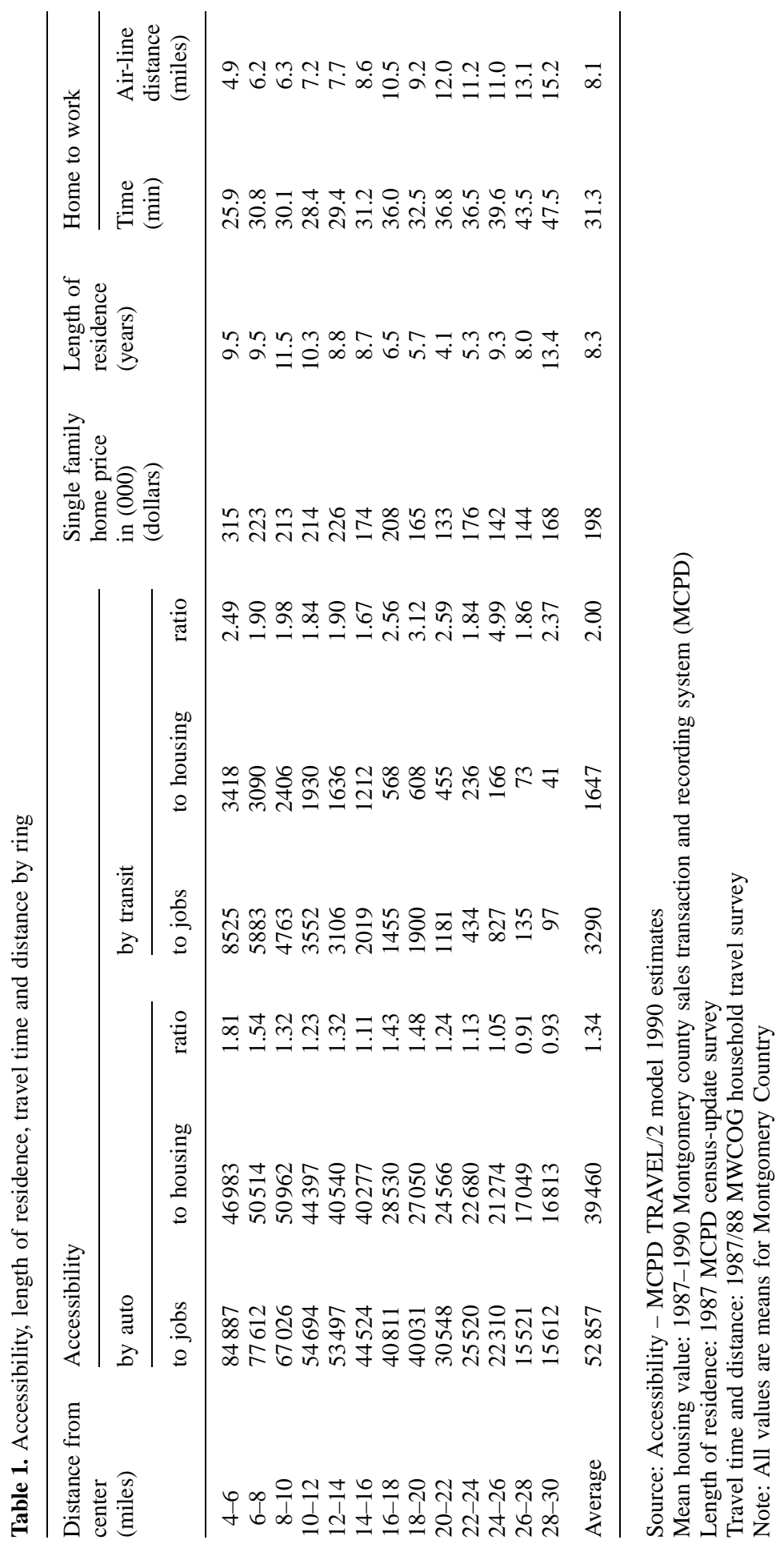


Table 2. The interaction of job and housing tenure

\begin{tabular}{|c|c|c|c|c|c|c|c|c|c|}
\hline \multirow{2}{*}{$\begin{array}{l}\text { Years at } \\
\text { same } \\
\text { firm }\end{array}$} & \multicolumn{4}{|c|}{ Average years in same residence } & \multirow{2}{*}{$\begin{array}{l}\text { Years at } \\
\text { same } \\
\text { residence }\end{array}$} & \multicolumn{4}{|c|}{ Average years at same firm } \\
\hline & Mean & Std. dev. & $n$ & $t$ & & Mean & Std. dev. & $n$ & $t$ \\
\hline 1 & 4.88 & 3.66 & 52 & $-2.50^{\mathrm{c}}$ & 1 & 4.19 & 3.39 & 36 & $-3.44^{\mathrm{c}}$ \\
\hline 2 & 5.14 & 3.88 & 49 & $-1.89^{\mathrm{a}}$ & 2 & 4.61 & 3.78 & 51 & $-2.90^{\mathrm{c}}$ \\
\hline 3 & 5.12 & 3.68 & 24 & -1.46 & 3 & 5.77 & 3.59 & 31 & -0.72 \\
\hline 4 & 4.89 & 3.19 & 29 & $-2.18^{b}$ & 4 & 4.80 & 3.81 & 25 & $-1.85^{\mathrm{a}}$ \\
\hline 5 & 6.84 & 4.09 & 18 & 0.59 & 5 & 5.26 & 3.18 & 26 & -1.52 \\
\hline 6 & 7.12 & 3.34 & 25 & 1.23 & 6 & 6.58 & 4.02 & 24 & 0.38 \\
\hline 7 & 5.35 & 3.77 & 14 & -0.88 & 7 & 4.13 & 2.72 & 15 & $-2.91^{\mathrm{c}}$ \\
\hline 8 & 5.64 & 3.63 & 17 & -0.69 & 8 & 8.25 & 3.05 & 12 & $2.20^{\mathrm{b}}$ \\
\hline 9 & 7.12 & 2.79 & 8 & 0.85 & 9 & 7.55 & 3.60 & 9 & 1.06 \\
\hline 10 & 6.87 & 4.17 & 16 & 0.57 & 10 & 8.50 & 3.74 & 8 & $1.67^{\mathrm{a}}$ \\
\hline $11+$ & 8.04 & 3.62 & 94 & $4.17^{\mathrm{c}}$ & $11+$ & 7.34 & 3.91 & 109 & $2.53^{\mathrm{c}}$ \\
\hline $\begin{array}{l}\text { Overall } \\
\text { mean }\end{array}$ & 6.26 & 3.84 & 346 & & $\begin{array}{l}\text { Overall } \\
\text { mean }\end{array}$ & 6 & 3.88 & 346 & \\
\hline
\end{tabular}

Source: 1991 Montgomery county travel panel survey, wave 1

Note: $t$ represents results of $t$-statistic from difference of means test

${ }^{a}$ Indicates statistically significant difference of means from population average at $90 \%$ level of confidence

b Indicates statistically significant difference of means from population average at $95 \%$ level of confidence

${ }^{c}$ Indicates statistically significant difference of means from population average at $99 \%$ level of confidence

shorter length of residence in these areas. Average length of residence declines from 9.5 years at a radius of 4-6 miles from downtown to 4.1 years at a radius of 20-22 miles. This radius is approximately the urbanized area boundary as defined by the Census Bureau. The average length of residence then picks up as farms and older pre-suburban structures replace new development in the landscape, rising to 13.4 years at 28-30 miles from downtown.

Accessibility to jobs is highest in the center of the region, and declines more or less steadily as one moves away from the center. Jobs accessibility declines at a faster rate than housing accessibility, as housing remains more suburbanized than employment. Therefore, the ratio of Jobs to Housing accessibility declines from a surfeit of jobs (ratio of 1.81 by auto) to relative scarcity (a ratio of 0.93 by autor at $28-30$ ) as one moves out from the center.

Two location variables are defined for the regression: distance (in miles) from the home to the center of the region (Lh), and distance between the workplace and the center of the region $(\mathrm{Lw})$. The center of the region is defined as the zero mile marker at the ellipse in front of the White House in Washington, DC. The home and work locations were identified by geocoding keyed to the home address and the workplace's nearest crossstreets. 


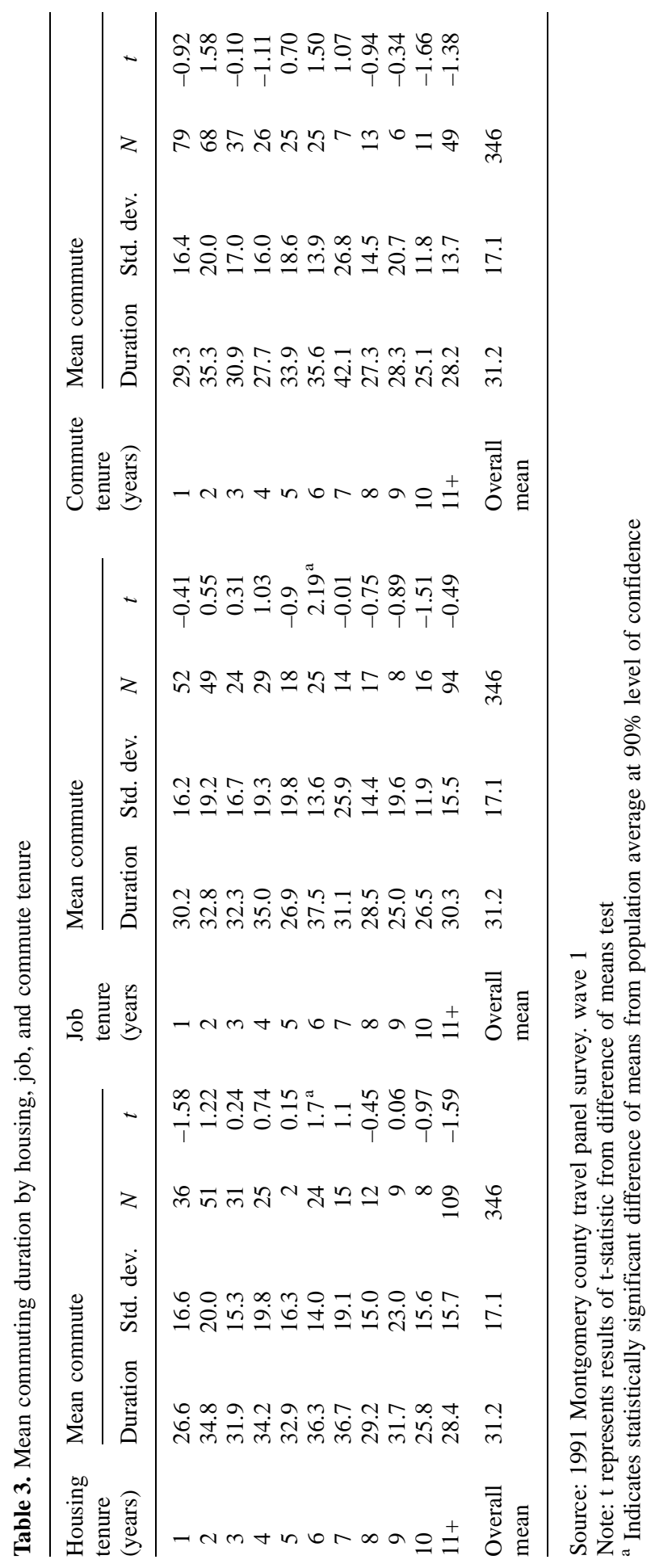




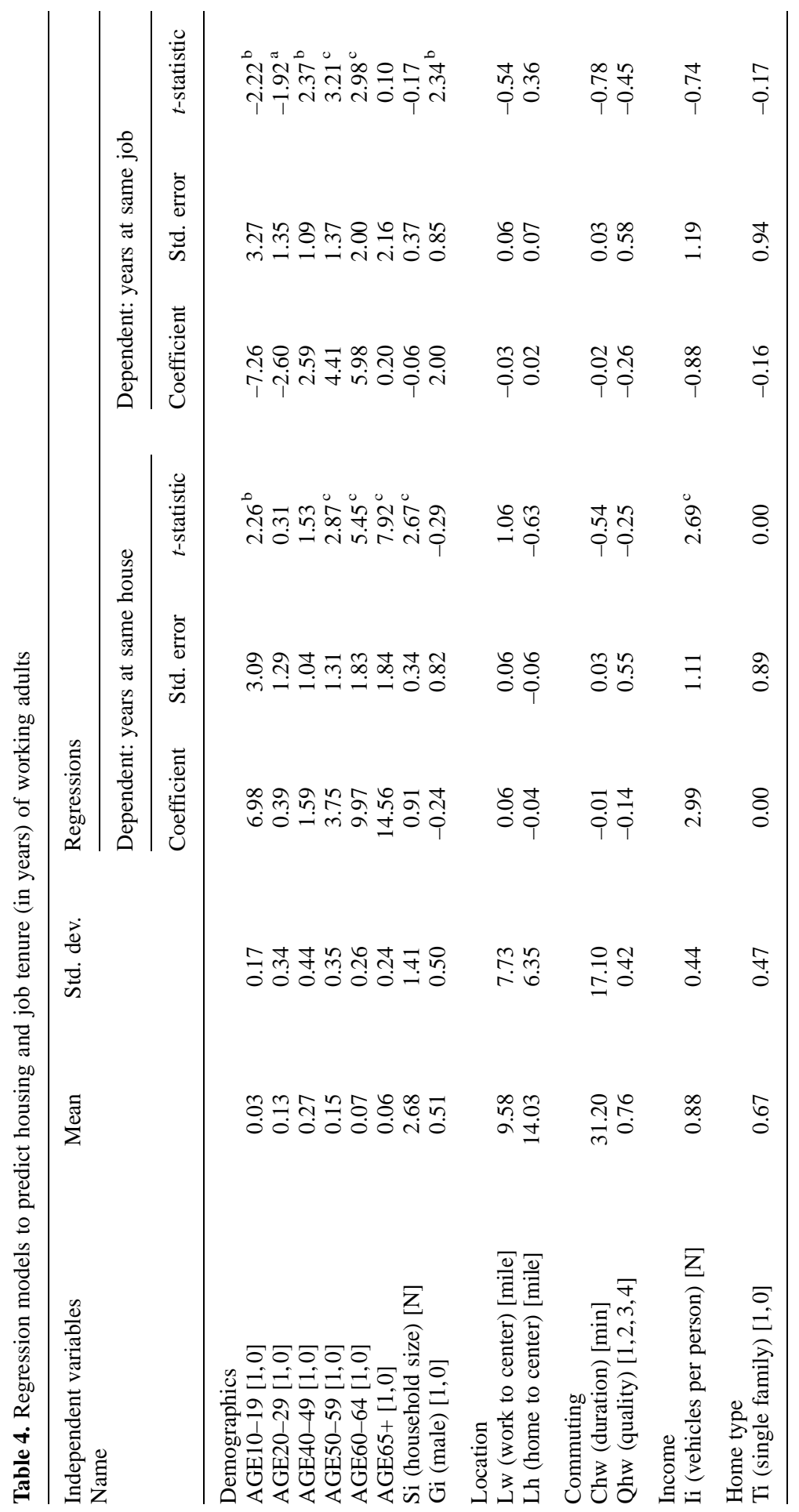




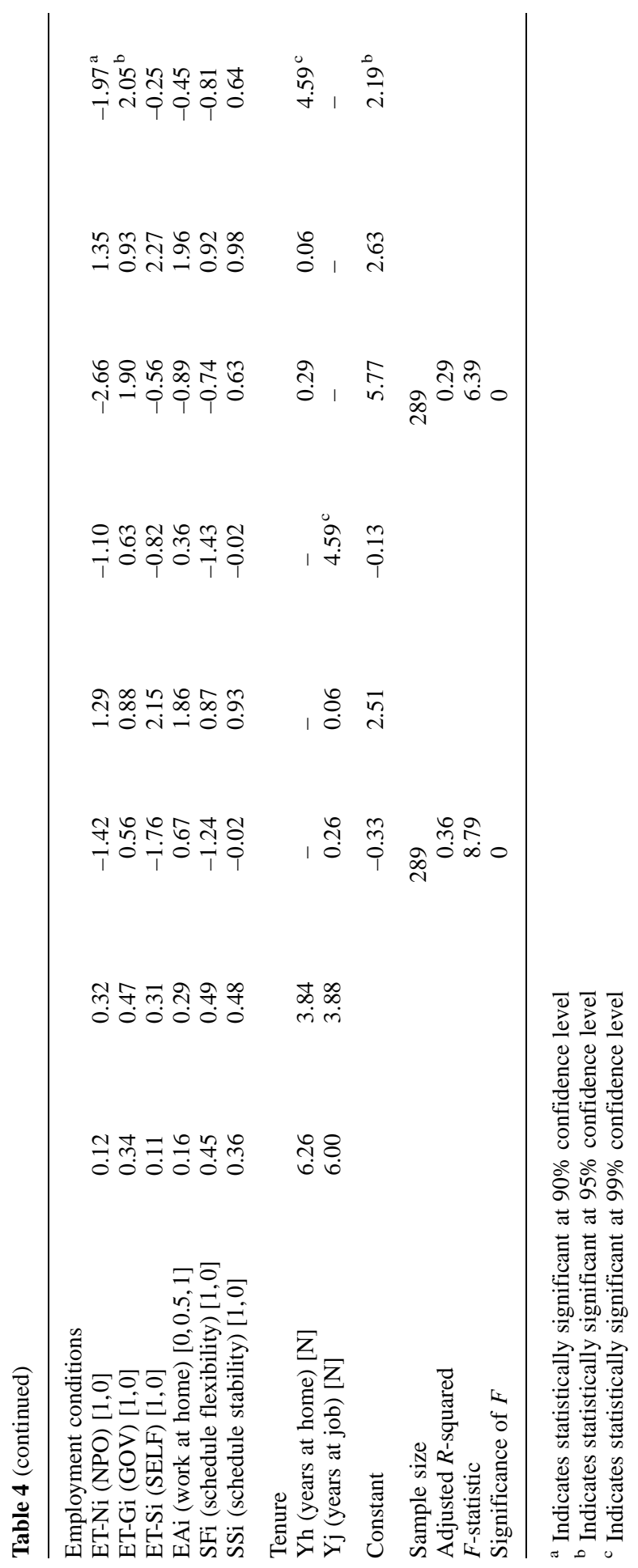


These variables control for at least two factors. The first is accessibility to opportunities and competitors. As shown in Table 1, accessibility to homes and jobs is largely a function of the distance from the center of the region. If accessibility has an important influence on tenure, it should be controlled for through the location variables. Second, and more importantly, location controls for the material duration of development, the age of the home and workplace. Logic requires that tenure in a home or workplace cannot exceed the age of that building. It follows that if the metropolitan area is relatively young, and if location and material duration of development are highly correlated, then there should be some spatial dependence of tenure on location. Unfortunately, the age of the housing unit, work site, and the tenure of the employer at that location are not known, so we must take this indirect approach. Because the largest amount of new development of housing and jobs is occurring away from the center of the region, we expect the distance from the home to the center of the region to be negatively associated with housing tenure $(\mathrm{Yh})$ and distance from the workplace to the center of the region to be negatively associated with workplace tenure (Yw). The cross-relationships between location of the workplace (Lw) and housing tenure $(\mathrm{Yh})$, and between housing location ( $\mathrm{Lh}$ ) and workplace tenure $(\mathrm{Yw})$ are second order effects, and are not expected to be significant.

It would be desirable to control for a third factor, the turnover rate of the neighborhood, however the sample size was not sufficient to establish whether different neighborhoods have varying turnover rates, above and beyond what would be expected for differences in age or distance from the center.

The results of the regression, presented in Table 4, indicate no statistically significant relationship between location and tenure after controlling for the other variables included in the regression. We can infer that the correlation between new construction and distance from the center is not strong enough to force the hypothesized result.

\section{Co-tenure}

This section analyzes the issue of "co-tenure". Co-tenure, or co-duration, is the positive relationship between tenure at a job and tenure at a house, and has been found to a limited extent in earlier studies (Fredland 1974; Weinberg 1979; Verster 1985). There are two principal reasons why we anticipate co-tenure. The first relates to changing incomes associated with changing jobs. If a new job results in a higher income, then that income can be used for better housing at a different location. This second move will show up in the data as a positive association of job with housing tenure. The second reason concerns changing travel times associated with changing jobs (or houses). As travel times change due to a new job location, the balance of the housing/travel trade-off is significantly altered. If the change of job or housing location is voluntary (resulting in an increased availability of choices due to higher welfare) individuals can adjust their other (housing or job) location to obtain better a house (job) at an equivalent commuting 
duration, or an equivalent house (job) at a shorter commuting duration, or some combination of the two. Thus co-duration of years at home and years at a job is supportive of the notion of mutual co-location.

By way of background information, the respondents to the Travel Panel Survey used in this study reported a length of residence of 6 years and an average length of employment with the same firm or agency of just over 6 years. However, the average time in the same commute, the shorter of the length of residence and length of employment was about 4.5 years.

Table 2 shows the interaction of switching jobs and switching homes. The hypothesis here, as suggested in earlier literature, is that mobility in one is associated with mobility in the other, that the decisions are not autonomous. By comparing the average years at a residence with the number of years with the same firm, it can be seen that recent job switchers have shorter than average stays in their house, and long-timers at jobs are long-timers at home. We anticipate then, that individuals with a job tenure below the regional average will have a housing tenure also below the regional average. Similarly, individuals with a job tenure above the regional average would be expected to have a housing tenure longer than average.

This was tested with a difference of means test comparing the overall average with the average for each one year subsample. The tests were statistically significant in 4 of 11 cases, all in the direction consistent with the co-tenure hypothesis. The second part of Table 2 shows this relationship the other way, the average number of years at the same firm for each year at a residence, and leads to the same conclusion, with 7 of the 11 cases statistically significant.

We can conduct the same tests in the context of a multivariate regression. We have defined two variables, length of tenure at a job (Yw) and length of tenure in a house ( $\mathrm{Yh}$ ), which serve as the dependent variables in the two regressions shown in Table 4. We use the job tenure as an independent variable where housing tenure is the dependent variable, and vice versa. It is expected that these will be positively correlated and statistically significant.

The tenure variables, year at the same job to predict house tenure and years at the same house to predict job tenure came out as expected and were statistically significant, corroborating the finding that these decisions are not autonomous.

\section{Commuting}

The theory developed above discusses the interaction of commuting time and job and housing tenure. Studies have been contradictory on its effects (Simmons 1968; Clark and Burt 1980). Cadwallader (1992), when modeling propensity to move as a function of the differential "stress" between the places being moved from and considered to be moved to, identified the commute length as one of many causes of stress. While in an era of rising point-to-point travel times, relocation can be used as an opportunity to maintain or reduce commuting costs, there is by necessity, shorter tenures 
associated with new development than existing housing, and new development is found disproportionately at the edges of the urban region, areas with relatively low accessibility to jobs and higher average commuting distances and times.

Table 3 shows the average home to work time, and its standard deviation, broken down for individuals by tenure of residence, job, and commute (the shorter of tenure of residence and job). The home to work time (Chw) is self-reported in minutes, for survey respondents on a Thursday in June 1991, taken from a travel diary. One observes that individuals who recently moved or changed jobs have slightly shorter than average commutes, as do individuals with many years at the same job or house. The first can possibly be explained by frequent job and housing switchers. This group is more likely to have a larger share of part-timers at work in lower skilled jobs which are ubiquitous across the landscape, and thus can be found closer to home. Those who have selected a low-skill job which they recognize to be of limtied duration, may be more likely to move into temporary quarters, for instance an apartment, near to work. The second may be explained by location: long timers are probably situated comfortably in the more established, more accessible areas of Montgomery County. But neither trend is strong or statistically significant.

In the regression analysis, two variables reflect commuting conditions. The first uses the same home to work time variable described above (Chw). If individuals relocate consciously with the intention of improving commuting conditions, then time will be expected to be positively associated with years at the same house or years at the same job. Alternatively, if aging in place in higher accessibility homes and jobs dominates, then time would have a negative sign.

The second variable reflects a self-reported assessment of the quality of the trip (Qhw). The question "How would you rate the traffic conditions for your work trip" offered four answers: "Good", "Acceptable", "Inadequate", and "Intolerable". These variables were scaled from 1 to 4 , with 1 being assigned if the trip was reported to be "Good" and 4 if the trip was "Intolerable". As with travel time, the anticipated sign on the quality variable depends on two offsetting factors, relocation to improve commuting conditions as opposed to aging in place with a quality commute. Thus we expect the same sign on the traffic conditions variables as on commuting time. However, it should be noted that as travel becomes more complex through such innovations as trip chaining, what is a high quality commute and what is a short or long commute will tend to diverge.

The coefficient on home to work time was not significantly different from zero on either regression. This does not imply journey to work time is an irrelevant factor, as if it were, the coefficient would likely be different from zero - a city with commutes distributed as if there were perfect entropy (a random distribution of worker's homes in relation to their workplace) would have significantly longer commutes than a city where individuals self-organize their home and workplace locations to contain commuting costs. Rather the result supports the notion that when individuals change 
jobs, they do so on average to jobs at approximately the same travel duration from their homes, or concurrently move their homes. The variable reflecting the quality of the trip similarly had no impact on either years at the same job or at the same home, indicating that trips are on the average of the same quality for people who have recently changed (jobs and/or houses) as for people who have not.

\section{Housing type}

Living in a single family dwelling unit type has been found to be among the most powerful predictors of residential mobility, as owner-occupiers are likely to have higher moving costs, greater flexibility in modifying their present home, and a greater commitment to the neighborhood (Michelson 1977; Speare, Goldstein and Frey 1974). We define a dummy variable for housing type (Ti), taking the value of one if the individual resides in a single family home. We expect the previous research to be corroborated here. However, it is clear that housing type is correlated with other factors, including age, income, and distance from the center of the region, so whether this relationship manifests itself is unclear.

The results of the regressions imply that housing type is statistically not significant. Perhaps the conversion of many apartments from rental to condominium over the past two decades have altered the commitment of apartment dwellers to their community.

\section{Income indicators}

Income is a factor which can be expected to be associated with tenure, however the literature here too is contradictory (Abu-Lighod and Foley 1960; Brown and Longbrook 1970; Fredland 1974). Changes in jobs, restarting the tenure variable at zero, result both in changes in location, as well as change in income. Higher incomes are typically associated with more specialized jobs. Since specialized jobs are, by their nature, less frequent, the costs of switching jobs are higher. If the costs of switching tend to outweigh the benefits, this may lead to an association with higher incomes and longer tenure. Comporting with this is the correlation of low incomes with rental housing.

A second relationship is between income and age. Typically higher incomes are associated with individuals who have built up skills and position in the workforce over time. Since age is associated with stability in the job and housing markets, we again expect income to be positively associated with tenure.

The income question on the survey was not answered consistently, so a surrogate measure was developed, vehicles per person. Vehicle ownership has been used widely in the transportation literature as a surrogate for income.

Vehicles per person was significant in explaining housing tenure, suggesting a positive association between wealth and length of stay in the 
same residence. However, it must be recognized that other variables which would inherently be associated with income - including age and household size - were already considered here. The coefficient on vehicles per person was not different than zero in the regression explaining jobs tenure.

\section{Demographics}

The dummy variables representing age cohort (AGE10-19, AGE20-29, AGE 40-49, AGE50-59, AGE60-64, AGE65+) are expected to be associated with job and housing tenure (AGE30-39 serves as the suppressed variable). As one ages, employment tenure is expected to rise, at least until AGE65+. Logic dictates that only by being older can an individual stay at a firm for a long time, a twenty year old cannot have worked for 25 years at the same job. Jobs held after the traditional retirement age of 65 may or may not show this effect, as part-time work as a share of employment is thought to increase. Similarly, as one ages from AGE20-29 onward, length of tenure in the same house should increase for similar reasons. However, those AGE 10-19 often still live at home with their parents, so the effect there is uncertain.

Gober et al. (1991) and Doorn and Van Rietbergen (1990) compare life cycle stage and mobility. Gober (1991) found that mobility is more important, and frequent, among non-families. While 19\% of households change structure in a given year, $18 \%$ move. "Spells" of household stability in a given place were measured: for nuclear families the average time was 6.94 years, compared to 4.77 years for loners, 4.16 years for couples with no children, 3.16 years for other families, and 1.78 years for unrelated persons.

Household size $(\mathrm{Si})$ may indicate the bondedness a person has to his or her current situation. As household size increases, relocation costs increase and the risk of switching (or quitting) one's job becomes more serious. For these reasons, it is expected that household size will be positively associated with both years at the same house and years at the same job.

The gender variable (Gi) takes a value of 1 if the individual is male and 0 otherwise (female or not-reported). Males are expected to have a longer average tenure at the workplace than females for two reasons. First, females are more likely to take time off for family reasons, such as raising children and caring for relatives. Second, for this reason and others, rates of labor force participation between the sexes have not yet equalized. There is not expected to be any effect of gender on years at the same house.

The age variables came out largely as hypothesized. As one ages, one has longer tenures at home and work. The key exceptions were at the edges, years at the same house for those under the age of 20 , and years with the same employer for those over the age of 65 . Those under 20 had more years at home than those 20-29, who probably recently moved out from their parent's home. Those over 65 and working did not have more years at the same job than those who were younger, suggesting that their work is of a different nature, perhaps part time, or a career shift occurred at the traditional retirement age. 
The size of the household was positively associated with housing tenure. This corroborates the notion that larger households have somewhat higher relocation costs (both monetary, and probably more importantly, social), and thus do so with less frequency. Household size was independent of years at the same job. As expected, males have been with the same firm longer than females. There was no relationship between gender and housing tenure.

\section{Employment conditions}

Several variables describe work conditions which may be associated with length of stay at an employer. Three dummy variables are used to describe the employer as government (ET-Gi), a non-profit organization (ET-Ni), or self-employed (ET-Si), while the plurality of private sector employees are considered the baseline. It is expected that government employees stay at the same job longer, as that is associated with civil service, while nonprofit workers have shorter than average job tenures because of their youth and/or part time job status and an assumption that they earn lower salaries.

Three employment condition variables are tested in an exploratory manner, it is possible that increased job tenure is associated with trust, and thus flex-time and work at home, as well as a more stable schedule, because unstable schedules may discourage staying with the same job. The null hypothesis is tested relating employment conditions to residential tenure. These variables are defined as follows: Flexibility is represented by a dummy variable (SFi) with a value of 1 if the respondent is able to choose his or her own schedule and 0 otherwise. Stability is measured by a dummy variable ( $\mathrm{SSi}$ ) which takes a value of 1 if the work schedule changes from day to day or week to week, and 0 otherwise. Employer attitude to at home work (EAi) is scaled as 0 if the employer never allows the employee to work at home, a 0.5 if the employee can sometimes work at home, and 1 if the employee can always work at home.

The variable representing the type of employer, gave results consistent with the hypothesis for job tenure. As opposed to private sector employees, government workers have stayed longer, while those at non-profits have stayed less time. Self-employed persons have on the average been in that status for a shorter time, but there is a wide variance and the results were not significant. Employer type did not have any influence on years at the same house, suggesting that any of these second order associations have already been accommodated through the job tenure variable.

The variables reflecting schedule stability, flex-time, and employer attitude toward at-home work, were not significant, indicating that job tenure and flexibility are not associated. Similarly, the second order effects of employer flexibility had no correlation with home tenure.

\section{Conclusions}

It has been noted in previous research that commuting durations are shortening nationally (Gordon, Jun and Richardson 1992) and holding 
steady in metropolitan Washington (Levinson and Kumar 1994b). The hypothesis for this was that individuals and firms mutually co-locate to contain commuting costs. If travel times were the only factor in new residential locations, those who recently moved should have significantly shorter than average commutes; if it were not a factor at all, recent movers should have a longer than average commutes to take advantages of lower home prices in undeveloped areas far from the metropolitan center. In fact length of residence and length of stay with a firm are largely independent of cummuting time. This points out that relocation is not an "all-or-nothing" decision, but rather that individuals try on average to maintain commuting times when switching, and that the increase in travel time due to further suburbanization of housing is offset by the suburbanization of employment. It also suggests that the demand curve of the marginal locator, the individual who is just making the decision, is very similar to that of the average individual, who could have made the decision at any point in the past.

Unfortunately, there are questions which cannot be directly answered from this data, but which will require additional waves of a panel survey. First, when a specific individual changes jobs, does his or her commute duration go up or down? How does this depend on who that individual is? Similarly, a study of individuals commutes to the same job before and after changing houses would be useful. The question of length of stay in the same house or job (or house and job), should become important to a new generation of dynamic urban transportation and land use planning models. This research only begins that investigation.

Acknowledgments. The author would like to thank David Gillen, Betty Deakin, Roger Stough, Kingsley Haynes, Chris Winters and Ajay Kumar, as well as two anonymous referees, for their review of earlier drafts of this paper. A previous draft of this paper "Location, Relocation, and the Journey to Work" was presented at the Western Regional Science Association Meeting in San Diega, CA in Feb. 1995, where it won the Tiebout Prize. The author would also like to acknowledge the help of the Montgomery County, MD Planning Department and the Institute of Transportation Studies at the University of California at Berkeley. The opinions expressed in this paper are those of the author and not his employer. 


\section{Endnote}

${ }^{1}$ A brief statistical analysis of the residuals from the regressions in Table 4 was performed. The data exhibit heteroskedasticity, as the size of the residual is positively associated with job and housing tenure, however the use of feasible generalized least squares did not result in noticeably different coefficients or change any of the conclusions, and so is not reported. The analysis of variance tables are given below.

Dependent Variable...

Years at Same House Yh

Analysis of Variance

$\begin{array}{lrcc} & \text { DF } & \text { Sum of Squares } & \text { Mean Square } \\ \text { Regression } & 21 & 7618.88892 & 362.80423 \\ \text { Residual } & 268 & 11064.91424 & 41.28699 \\ \text { F }=8.78737 & & \text { Significance F }=0.0000 & \\ \text { Dependent Variable ... } & & \text { Years at Same Workplace Yw } \\ \text { Analysis of Variance } & & & \\ & \text { DF } & \text { Sum of Squares } & \text { Mean Square } \\ \text { Regression } & 21 & 6178.72615 & 294.22505 \\ \text { Residual } & 268 & 12334.35565 & 46.02372 \\ \text { F }=6.39290 & & \text { Significance } F=0.0000 & \end{array}$

\section{References}

Abu-Lughod J, Foley MM (1960) The consumer votes by moving. In: Foote NN, AbuLughod J, Foley MM, Winnick L (eds) Housing Choices and Housing Constraints. McGraw-Hill, New York 134-178

Bell DA (1991) Office location - city or suburbs? Transportation 18:239-259

Bennett DG, Gade O (1979) Geographic perspectives in migration research: A bibliographical survey. University of North Carolina at Chapel Hill, Department of Geography: Studies in Geography \# 12

Brown LA, Longbrake DB (1970) Migration flows in intra-urban space: place utility considerations. Annals of the Association of American Geographers 60(2):368-384

Cadwallader M (1982) Urban residential mobility: a simultaneous equations approach. Transactions of the Institute of British Geographers, n. s. 7:458-473

Cadwallader M (1992) Migration and residential mobility: macro and micro approaches. University of Wisconsin Press, Madison, WI

Cervero R, Landis J (1992) Suburbanization of jobs and the journey to work: a submarket analysis of commuting in the San Francisco bay area. Journal of Advanced Transportation 26:3

Clark WAV, Burt JE (1980) The impact of workplace on residential relocation. Annals of the Association of American Geographers. 70:59-67

Clark WAV, Moore EG (ed) (1980) Residential mobility and public policy. Vol 19: Urban affairs annual reviews. Sage Publications, Beverly Hills

Daniels PW (1972) Transport changes generated by decentralized offices. Regional Studies 6:273-289

Doorn PK, Van Rietbergen A (1990) Lifetime mobility: interrelationships of labor mobility, residential mobility, and household cycle. Canadian Geographer: 34:33-48

Forrester J (1969) Urban dynamics. MIT Press, Cambridge, MA, p 121

Fredland D (1974) Residential mobility and home purchase. Lexington Books, Lexington, MA 
Giuliano, G, Small KA (1993) Is the journal to work explained by urban structure? Urban Studies, Vol 30, No 9, pp 1485-1500

Gordon P, Richardson HW, Jun MJ (1991) The commuting paradox: evidence from the top twenty. Journal of the American Planning Association 57, 4:416-420

Gober P, McHugh K, Reid N (1991) Phoenix in flux: household instability, residential mobility, and neighborhood change. Annals of the Association of American Geographers 81(1): 80-88

Hayashi Y. Tomita Y (1989) A micro-analytic residential mobility model for assessing the effects of transport improvements in selected proceeding of the fifth world conference on transport research. Vol IV, Transport policy, management and technology towards 2001. Yokohama, p D91-D105

Kingkade WW (1983) Residential mobility, workplace relocation, and the journey to work. Doctoral dissertation

Knox P (1991) The restless urban landscape: economic and socio-cultural change and the transformation of metropolitan Washington, DC. Annals of the Association of American Geographers 81(2):181-209

Kumar A, Replogle M (1992) Low-cost travel panel survey. Presented at first US conference for panels for transportation planning, Lake Arrowhead, California, Oct 25-27, 1992

Levinson D, Kumar A (1994a) Operational evidence for changing travel patterns. ITE Journal, April 1994, pp 36-40

Levinson D, Kumar A (1994b) The rational locator: why travel times have remained stable. Journal of the American Planning Association, Summer 1994, 60(3):319-332

Levinson D, Kumar A (1995) Activity, travel and the allocation of time. Journal of the American Planning Association, Autumn 1995, 61(4):458-470

Michelson (1977) Environmental choice, human behavior, and residential satisfaction. Oxford University Press, New York

Montgomery County Planning Department (1987) Census-update survey

Montgomery County Planning Department (1993) Evaluation of a panel survey design for the collection and analysis of travel survey data. Silver Spring, MD

Moore EG (1971) Comments on the use of ecological models in the study of residential mobility in the city. Economic Geography 47:73-85

Verster ACP (1985) Commuting costs and the residential mobility of job changers. Transportation Planning and Technology 10/3:193-207

Quigley JM, Weinberg DH (1977) Intra-urban mobility: a review and synthesis. International Regional Science Review 2:41-66

Schneider W, Stahl K, Struyk R (1984) Residential mobility in the United States and the Federal Republic of Germany. University of Dortmund

Simmons JW (1968) Changing residence in the city: a review of intra-urban mobility. Geographical Review 58:622-651

Speare A, Jr Goldstein S, Frey WH (1974) Residential mobility, migration and metropolitan change. Cambridge, Ballinger, MA

Vickerman RW (1984) Urban and regional change, migration, and commuting - the dynamics of workplace, residence, and transport choice. Urban Studies 21:15-29

Wachs M, Taylor B, Levine N, Onh P (1993) The changing commute: a case study of jobshousing relationship over time. Urban Studies 30/10:1711-1730

Weinberg DH (1979) The determinants of intra-urban household mobility. Regional Science and Urban Economics 9:210-246

Wegener M (1994) Operational urban models: state of the art. Journal of the American Planning Association 60, 1:17-30 